\title{
Development of comparative investigation method for timing chain wear analysis using oscillating tribometer
}

\author{
L. Paulovics ${ }^{1, *}$, R. Kuti ${ }^{2}$, J. Rohde-Brandenburger ${ }^{1}$, \\ Cs. Tóth-Nagy ${ }^{1}$
}

${ }^{1}$ Széchenyi István University, Department of Internal Combustion Engines and

Propulsion Technology, Egyetem tér 1., 9026 Györ, Hungary

${ }^{2}$ Széchenyi István University, Department of Mechatronics and Machine Design

Egyetem tér 1., 9026 Győr, Hungary

*e-mail: paulovics.laszlo@sze.hu

Submitted: 17/05/2021; Accepted: 03/08/2021; Published online: 30/08/2021

Abstract: This paper presents the development of a test procedure to investigate timing chain components under abrasive stress on a tribometer. Engine developers use cost and time expensive engine dynamometer tests to investigate timing chain life expectancy under different conditions. Tribometer tests are fast and cost effective, but these use standardized specimen material and geometry that greatly differ from the original tribological system of the timing chain. Manufacturing specimens from the original chain material using the original technology is complicated; surface quality and hardness properties cannot be guaranteed. The aim of research was to develop a test method for rapid and cost-effective comparison of engine lubricants, timing chain materials or coatings, as well as to assess the wear resistance of the chain to contaminants. Various uncontaminated and carbon black blended lubricants were compared using standard-based ball-on-disc tribometer tests to tribometer tests using actual timing chain components (bush-on-pin test) of a Diesel engine. Lubricants were ranked in terms of coefficient of friction and wear. Results showed that bush-on-pin tests were comparably suitable for testing lubricants when evaluated against standard ball-on-disc tribometer tests.

Keywords: timing chain; wear measurement; tribometer, motor oil, soot, 


\section{Introduction}

The trend of engine development over the last 20 years (reduction of mechanical losses, increase of specific power, start-stop systems, hybridization, etc.) increased the load of timing chains similarly to most engine components. In addition to the increasing load, it is also a challenge that the timing chain is especially sensitive to the quality of the lubricant [1] [2]. Due to low viscosity motor oils, increasing oil change intervals and the soot formation (especially in Diesel engines, but it is already characteristic of gasoline engines as well), under certain conditions chain wear may be higher than planned or permitted [3].

Timing chain wear adds up at each link and can be measured as chain elongation, that can cause various problems during engine operation. Due to the elongation of the chain, valve timing is shifted, resulting in a loss of power and a deterioration of the emission values. In addition, as the chain elongates, the chances of the chain breaking or the chain jumping over the sprocket (one or more teeth) increase. These faults could cause immediate engine damage. It is therefore necessary to improve timing chains continuously, to adapt to changing conditions and new types of motor oils [1] [2].

In the field of engine development, long-term engine tests and radionuclide technology (RNT) wear measurements are used to test chain wear [4] [5], but due to the high cost and time required of these test methods, a compromise must always be made in the measurement program. This means that the number of variations of engine working point and oil quality is limited. In the case of tests performed on the engine dynamometer, the occupancy and operation of the dynamometer and the fuel consumption represent a significant time requirement and cost. In the case of RNT wear measurement, the high activation cost of the components and the management of the radioactive components and waste must also be taken into consideration. It is also a problem that under normal engine load, it can take hundreds of engine working hours to produce measurable wear. In addition, the carbon footprint of these tests is also significant.

Testing chains, chain segments or chain links on a component test bench or tribometer can provide an opportunity to replace expensive engine tests. However, such test methods are still novel for timing chains, at least they are rarely used [6]. Therefore, it is necessary to develop and analyze similar methods for correlation with wear processes in the real environment.

\section{Levels of tribological testing}

There are several levels of tribological testing available for testing timing chains (like any machine part). According to Czichos and Habig [7] these can be: 
I. Field test: test of the original and complete tribological system under original operating conditions (in case of timing chains, it means invehicle test)

II. Dynamometer test: examination of the original and complete tribological system on nearly realistic load on a dynamometer. (in case of timing chains, it means vehicle dynamometer test)

III. Subsystem test: examination of subsystems, component groups under nearly realistic conditions. (in case of timing chains, it means engine dynamometer test)

IV. Component test: testing of original or simplified components under conditions similar to the real ones. (in case of timing chains, it means a chain drive test bench)

V. Simplified component test: examination of specimens similar to the real part under conditions similar to the real ones. (in case of timing chains, it means testing of chain segments, links or chain-like specimens)

VI. Model test: a test performed on special test specimens under arbitrarily defined conditions for the purpose of basic research of friction and wear processes. (in case of timing chains, it means simple specimens modeling chain links - but in shape and material very different from it - at a different load from the original)

Moving from field test to model test, the real system is more and more simplified, with the obvious disadvantage of moving away from reality. However, simplifying complex systems - while retaining important parameters from the viewpoint of the examination - offers a number of benefits: cost, time and material requirements, and ecological footprint of the testing can be reduced.

In case of simplified component and model tests, the relevant parameters correspond to reality, but other test parameters are standardized for the purpose of cost-effectiveness, comparability and the simpler and more efficient exploration of causal relationships. In practice, this means that for example the material of the specimens and the quality and temperature of the lubricant correspond to the real operating conditions, but the shape of the specimens, the contact surface, the magnitude of the load are standardized, they do not want to follow the reality. Thus, the effect of irrelevant factors can be ruled out.

There are only few researchers dealing with wear testing of timing chains, and therefore the range of testing technologies used is not very wide. Mostly a test engine, possibly a component test bench, i.e. a chain test bench, is used, but just a few are involved in model testing. The using of a component test bench can seem to 
be an obvious solution, but its big disadvantage is that a custom special machine has to be developed for it. Due to the scarcity of the field, it is not profitable to develop such a special purpose machine for sales purposes. Therefore, even worldwide a small number of research institutes or development centers performing chain drive development design and create a chain test bench for their own use, according to their own needs, e.g. the Institute of Machine Elements, Gears, and Transmissions (MEGT) at the University of Kaiserslautern [6] [8] [9] [10].

The advantage of tribometer tests is that they are generally flexible in design to be suitable for testing a variety of specimens. Thus, for existing, commercially available tribometers, only a single specimen clamp needs to be developed and manufactured for chain link testing at minimal cost. However, its applicability is limited, and since it is a highly simplified tribological system compared to the original part, it is absolutely necessary to validate the results obtained with this method. Due to the narrowly used method, there is neither a mature target machine or adapter suitable for holding chain links and chain segments, nor a measurement method or standard, therefore it is necessary to develop such methods individually.

In the following, the method for wear testing of timing chain elements on tribometer is compared to the method of standardized ball-on-disc tribometer test in order to validate the results of the first one. Research was performed in the tribology laboratories at the Department of Internal Combustion Engines and Propulsion Technology at Széchenyi István University.

\section{Comparative experimental investigations on tribometer}

\subsection{Ball-on-disc model tests performed on ball-on-disc tribometer}

There are several tests defined by international standards for the qualification and comparative testing of lubricating oils and greases [11] [12] [13]. Of these, the 4ball-test is most commonly used to test greases [11]. To compare lubricating oils, the ball-on-disc test is also used, in which a ball of a bearing is pressed onto the planar surface of a disc at a given load, reciprocating the ball at a given frequency and stroke [13]. The wear and friction between the two is reduced by the lubricating oil passed between the contact surfaces.

\subsubsection{Methodology of ball-on-disc measurements}

In the ball-disc assembly (Fig. 1.), the specimens are in a point-like contact or they come in contact with a small contact surface close to it, so the tribological system operates in a mixed lubrication regime. Thus, the effect of additives and contaminants in the oil is definitely shown. The purpose of such tests is therefore to test the system in a mixed lubrication regime. 
The tribometer can measure friction online using built-in load cells, while wear can usually be determined after the tribometer test by measuring the size of the wear mark - in case of ball specimens wear scar diameter (WSD).

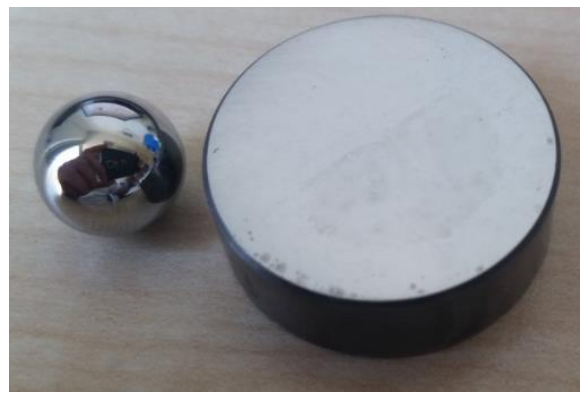

Figure 1. Ball-on-disc specimens

In the Department of Internal Combustion Engines and Propulsion Technology, such tests are used for various oil qualification, oil comparison tests, and the effects of oil additives and contaminants. These tests are performed on an Optimol SRV®5 tribometer [14]. In the last years, more than 500 new, used, aged and contaminated oil samples have been compared with this test, and the results showed a significant difference between different new (unused, uncontaminated, unaged) oils as well as between differently contaminated and used oils in terms of both friction and wear.

The material of the disc used in the test is 100Cr6, its surface is lapped and its surface roughness $\mathrm{Rz}$ is between $0.5-0.65 \mu \mathrm{m}$. The other part is a standard $100 \mathrm{Cr} 6$ bearing ball with polished surface. Additional parameters for the specimens are shown in Table 1.

Table 1. Parameters of the ball-on-disc specimens

\begin{tabular}{|c|c|c|c|c|}
\hline specimen & material & dimensions & hardness & roughness \\
\hline ball & $100 \mathrm{Cr} 6$ & $\varnothing 10 \mathrm{~mm}$ & $61.5 \mathrm{HRC}$ & $\mathrm{Ra} 0.02 \mu \mathrm{m}$ \\
\hline disc & $100 \mathrm{Cr} 6$ & $\varnothing 24 \times 7.9 \mathrm{~mm}$ & $62 \mathrm{HRC}$ & $\mathrm{Ra} 0.047 \mu \mathrm{m}$ \\
\hline
\end{tabular}

The test parameters are based on ISO 19291: 2016 [13], with the exception that the load is $150 \mathrm{~N}$ instead of $300 \mathrm{~N}$ and the temperature is $100^{\circ} \mathrm{C}$ instead of $120^{\circ} \mathrm{C}$. In addition, instead of the $3 \mathrm{ml}$ of oil required by the standard, a peristaltic pump provides continuous oil circulation, so the heat removal is continuous from the contact surface and the operation of the tribological system is stable, approaching the conditions in a real tribological system. The examination parameters are shown in Table 2. 
Table 2. Examination parameters of the ball-on-disc test

\begin{tabular}{|l|c|c|c|c|c|c|}
\hline & stroke & frequency & load & time & oil flow & temp. \\
\hline step 1. & $1 \mathrm{~mm}$ & $50 \mathrm{~Hz}$ & $50 \mathrm{~N}$ & $30 \mathrm{~s}$ & $225 \mathrm{ml} / \mathrm{h}$ & $100^{\circ} \mathrm{C}$ \\
\hline step 2. & $1 \mathrm{~mm}$ & $50 \mathrm{~Hz}$ & $150 \mathrm{~N}$ & $2 \mathrm{~h}$ & $225 \mathrm{ml} / \mathrm{h}$ & $100^{\circ} \mathrm{C}$ \\
\hline
\end{tabular}

All of these changes are necessary because during standard tests, the system was overloaded with frictional heat in the first half hour, which resulted that the oil lost its lubricity and the surface burned and then was severely worn. This phenomenon can be attributed to the fact that the standard has not been developed specifically for motor oils, that have a much lower viscosity compared to average lubricating oils (e.g. gear oils).

On the contact surfaces, the evaluation of the wear is based on the diameter (on the ball) and width (on the disc) of the wear scar. Measurements were performed using a Keyence VHX-1000 digital microscope. Fig. 2. illustrates the wear scar diameter measured on the ball, that was used for the evaluation.

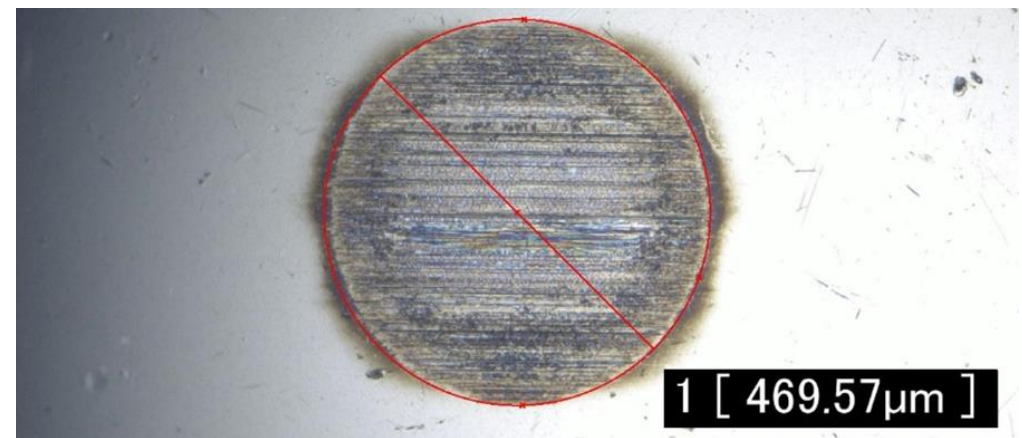

Figure 2. Wear scar on the ball specimen measured by digital microscope

During the test, the coefficient of friction was continuously measured. However, just the mean of the last 10 minutes was considered for the evaluation, because it was always stable enough.

The method presented above was developed for the purpose of comparing and ranking engine lubricants. It was important that the test was not specified for a specific engine part and could be repeated at any time. Because the goal was to create a database, it was important that the specimens were available anytime, in constant quality. Therefore, standard test specimens were used. The 100Cr6 material of these can be considered neutral in terms of all components of an average engine, this material or similar is mostly used as the material of camshafts, valve lifters or rocker arm rollers. 
The tested timing chain is from a V6 Diesel engine with a factory oil of Shell Helix Ultra Professional AV-L 0W-30, which was the reference oil. It was compared to two additional new oils from different viscosity grades (Castrol Edge Professional TWS 10W-60, Castrol BOT 920 0W-20) and versions of Shell Helix Ultra Professional AV-L 0W-30 mixed with different concentrations of carbon black. Hereinafter, the tested oils will be referred by their manufacturer and viscosity grade.

Carbon black is primarily used for industrial goals, generally as black color pigment, e.g. coloring tires. It can be used to replace engine soot generated during the combustion process of Diesel engines [15] [16] [17]. This is a commonly used method in tribological research, as it makes possible to control of quantity and quality of soot in the oil. In the case of real engine soot (generated in engine combustion process on test bench or vehicle), the repeatable quality and quantity cannot be ensured. Uy et al. [15], and La Rocca et al. [18] have shown that the quality of soot samples taken from an engine depends strongly on many factors: engine type, engine operation mode, and even the sampling location inside the engine. In the research, Cabot Monarch ${ }^{\circledR} 430$ carbon black was mixed into the fresh oil samples in concentrations of $0.5 \mathrm{wt} \%, 1 \mathrm{wt} \%$ and $2 \mathrm{wt} \%$, using magnetic stirrer as first step (1000 rpm, $10 \mathrm{~min})$, then ultrasonic homogenizer $\left(70^{\circ} \mathrm{C}, 15 \mathrm{~min}\right)$ and as last step magnetic stirrer (1000 rpm, $5 \mathrm{~min}$ ) again.

Due to the mixed lubrication regime, the measurable difference in friction can be expected not from the different internal friction of the oil, but from the realized lubrication regime, how efficient the oil and its additives can form a coherent lubricating film on the surface, how much load the lubricating film can withstand and how its anti-wear effects are deteriorated by contaminants.

\subsubsection{Results of ball-on-disc measurements}

The measurements were performed at $100{ }^{\circ} \mathrm{C}$, so the warm viscosity of the oils was decisive. At least 3 tribometer tests were performed with each oil sample and the mean values and standard deviation of the coefficient of friction $(\mathrm{CoF})$ were calculated and are shown in Fig. 3.

The coefficient of friction was lowest with Castrol 10W-60 oil, followed by the Castrol 0W-20, which preceded the Shell 0W-30 oil. It should be noted that the listed oils differ significantly not only in their viscosity but also in their additives, so the differences in friction and wear values depend on the additive package at least as much as on the viscosity. It was not the aim in this case to explore the cause of the differences between the oils and to examine the additive packages.

In case of oils mixed with carbon black (CB), it can be observed that the coefficient of friction increased slightly with the concentration of carbon black. 


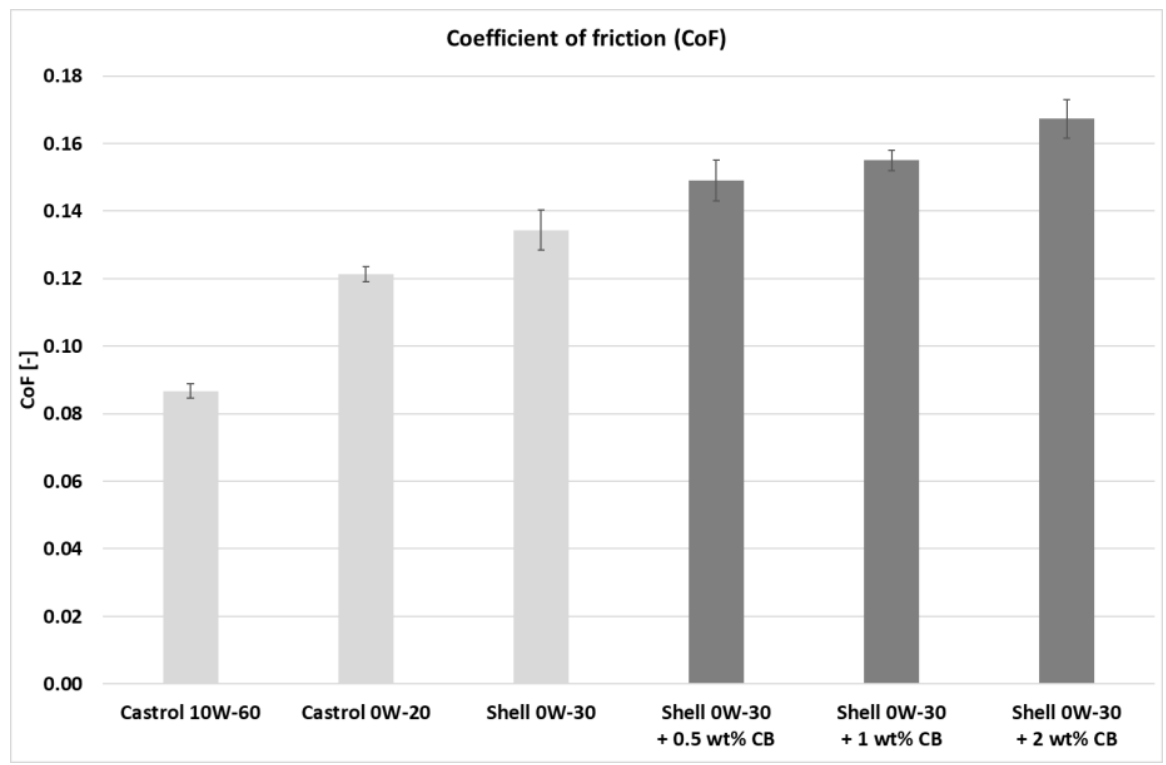

Figure 3. Coefficient of friction values measured with different oils on a ball-ondisc tribometer

In case of the wear scar diameters (Fig. 4.), a similar order has developed to the case of the coefficient of friction. This is logical in light of the fact that the thinner oil film presumably allowed more metallic contact between the surfaces. Therefore, both friction and wear were higher, although anti-wear and other additives also have a big impact on this process. Of the fresh oils, the high viscosity Castrol 10W-60 oil was clearly the best, followed by Castrol 0W-20 and Shell 0W-30 oils.

The effect of soot on the operation of Shell $0 \mathrm{~W}-30$ oil is all the more interesting. By adding $0.5 \mathrm{wt} \%$ and $1 \mathrm{wt} \%$ carbon black, the wear increased slightly, but not in proportion to the carbon black content. This is also related to the increase in friction. Here, it can be stated that the low carbon black content increased the stochasticity of the process. However, with a 2 wt $\%$ carbon black content, wear increased sharply. This phenomenon was expected regarding the observations of Ratoi et al. [19], Antusch et al. [16], and Hu at al. [17]. Through various tribological and chemical studies, they have found that carbon black - in addition to its abrasive effect - is strongly bound to metallic surfaces and to the anti-wear additives due to its polar structure. Therefore, the carbon black binds strongly to the metallic surface, isolating it from anti-wear additives, and also binds anti-wear additives, from which it does not get enough on the metallic surface to form a wear-resistant protective layer. 


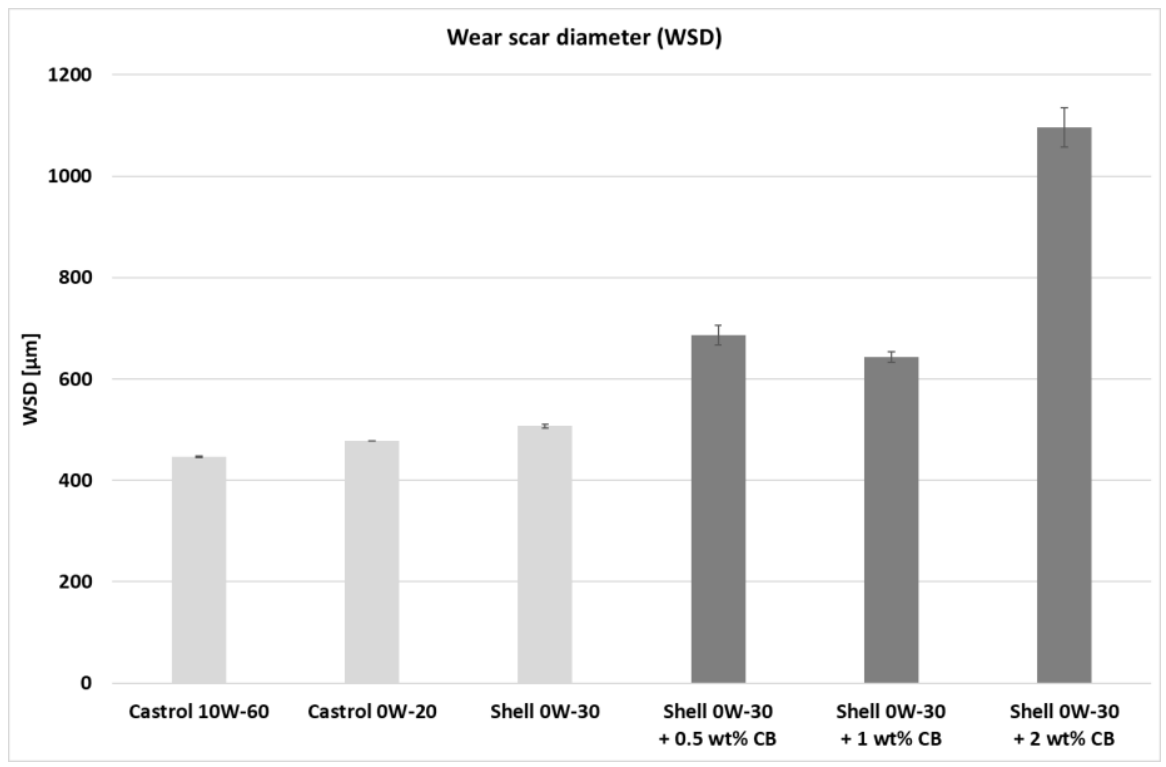

Figure 4. Wear scar diameter values measured with different oils on a ball-on-disc tribometer

Thus, the critical value for the carbon black content in this case were somewhere between $1 \mathrm{wt} \%$ and $2 \mathrm{wt} \%$ with this oil. This was in line with preliminary expectations, as $2 \mathrm{wt} \%$ soot content is typically the critical limit for Diesel engine lubricants according to experiences with MOL LubCheck.

A series of tribological tests were also performed on timing chain elements with the same oil samples. The purpose of this was to validate the specimen test with the model test.

This was necessary because specimen testing is a process under development and therefore results need to be validated. Ball-on-disc model testing is based on a widely used standard, it has been used for a long time in the department, and its results were reliable [20][18]. Therefore, it can be used as a reference in the development process of bush-on-pin specimen tests, performed on tribometer. 


\subsection{Chain bush-on-pin specimen tests performed with chain elements on tribometer}

There is a Plint TE-77 reciprocating tribometer at the department that was used for experimenting with wear testing of timing chains.

\subsubsection{Methodology of bush-on-pin measurements}

On the department's tribometers (and on the most type of tribometers in general), it is not possible to test the chain joints in the original ("pin-in-bush") configuration and on load similar to the original, the chain links are tested in a "bush-on-pin" configuration instead of the original configuration "pin-in-bush".

In case of a bush chain, the outer surface of the bush (in case of a tooth chain, the back of a moving plate) is pressed onto the surface of a pin fixed in the stationary clamp while reciprocating it at a given stroke and frequency, see Fig. 5.

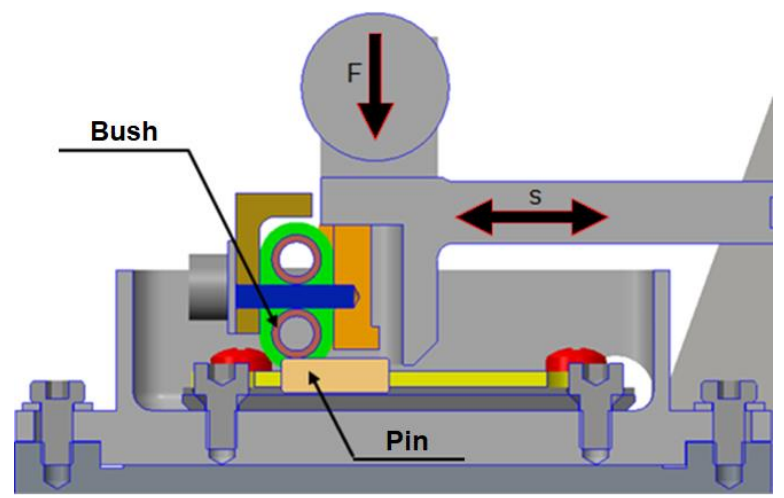

Figure 5. Position of the bush and pin in the reciprocating tribometer

The obvious disadvantage of the bush-on-pin method is that the model moves away from the real system by one step. However, it is still closer to the original tribological system than the ball-on-disc model used to classify lubricants [13], because the original material qualities are used. A further advantage over the real chain (pin-in-bush) assembly is that a point-like contact surface is created instead of a linear one (similar to the ball-on-disc test). This speeds up wear on one hand, and less uncertainty in the results can be expected on the other hand, because it is less sensitive to assembly inaccuracies (e.g. angular misalignment between the bush bore and the pin axis) and the deviation in the production quality (actual size within the tolerance field) of the parts has also much less influence. 
An additional advantage is that due to the higher surface pressure (initially the $\mathrm{p}_{\max }$ is around 2,9 $\mathrm{GPa}$ - approximate calculation in the absence of knowledge of the exact material properties) the parts wear faster, so the tests can be shorter.

It has to be mentioned, that hardness and surface quality of the bushes are very similar on their outer and inner surface, so it does not have more influence on the tribological behavior than the point-like contact instead of line-like. The hardness values were 880 to $970 \mathrm{HV}$ on the outer and 820 to $920 \mathrm{HV}$ on the inner surface. Also roughness parameters were of a similar magnitude, $\mathrm{Rz}$ values of the outer surface were around $1.3 \mu \mathrm{m}$, inner surfaces around $1.0 \mu \mathrm{m}$.

The bush-on-pin tests are suitable for relative comparison, like model tests. It may be suitable to compare different oil qualities, taking into consideration the given material quality of the chain, or to compare different chain material qualities and coatings.

The comparison of oils is based on coefficient of friction $(\mathrm{CoF})$ and wear scar diameter (WSD). The advantages of using WSD as wear indicator are, that it is simple and fast to measure, and it is comparable to standardized ball-on-disc tests, where WSD is the standard indicator [13]. Other opportunities are weighing the specimens and 3D scanning the wear scars, but the weighing in this order (tens to hundreds of micrograms) is unreliable (because of the residual oil and wear particles in case of imperfect cleaning), 3D scanning is very time-consuming and hard to compare to standardized tests.

The whole test procedure with the chains (the custom-made chain clamps, the test parameters and the wear measurement procedure) had to be developed in several steps in order to eliminate errors and reduce measurement uncertainty [21] [22].

As a result of the improvements, the uncertainty of the wear measurement (relative standard deviation of the WSD) was reduced from a value of above $50 \%$ to below $10 \%$ in all cases, moreover, in most cases it was below $5 \%$ [23]. However, this required compromises in the measurement program. At the relatively high stroke (first $6 \mathrm{~mm}$, later $4 \mathrm{~mm}$ ) and high frequency $(40 \mathrm{~Hz})$ initially used, due to the construction of the reciprocating tribometer (component elasticity, oscillations caused by clearance of components), during the test, the moving clamp stochastically shifted with the specimen in lateral direction. Therefore, instead of the previously used $4 \mathrm{~mm}$ stroke and $40 \mathrm{~Hz}$ frequency, in the final version of the test procedure 1 $\mathrm{mm}$ stroke and $10 \mathrm{~Hz}$ frequency were used. To compensate the large reduction in distance traveled by the specimens and its wear, the 2-hour duration of the tests had to be increased to 22 hours.

With the new parameters, the uncertainty (standard deviation of WSD) became small enough to allow a comparative test on different oil samples. 
The Lubrication was provided in a $15 \mathrm{ml}$ oil bath, which completely covered the pin fixed in the stationary clamp. The test parameters are given in Table 3.

Table 3. Final parameters of the bush-on-pin test

\begin{tabular}{|c|c|c|c|c|c|}
\hline stroke & frequency & load & time & oil vol. & temperature \\
\hline $1 \mathrm{~mm}$ & $10 \mathrm{~Hz}$ & $50 \mathrm{~N}$ & $22 \mathrm{~h}$ & $15 \mathrm{ml}$ & $100{ }^{\circ} \mathrm{C}$ \\
\hline
\end{tabular}

The chain components were from the timing chain of a passenger car's Diesel engine, which is a bush chain by type. The pins were chrome-plated and had a hardness of at least $1500 \mathrm{HV}$. The surface of the bushes was carbonitridated and their hardness was at least $700 \mathrm{HV}$.

For the tests, a new timing chain was disassembled, and a pin and bush were installed in the tribometer for each test, as shown in Fig. 5. Due to the large difference in hardness, wear occurred practically only on the bush, the wear of the pins was negligible and hardly measurable.

The coefficient of friction $(\mathrm{CoF})$ was measured during the test, the wear scar diameter (WSD) on the bush was measured with a digital microscope after the test. To evaluate and compare the CoF values, the mean value of the last hour was always considered, because it was always stable enough at the end of the tests. The amount of wear was defined from the average of two diameters of the wear scar, see Fig. 6.

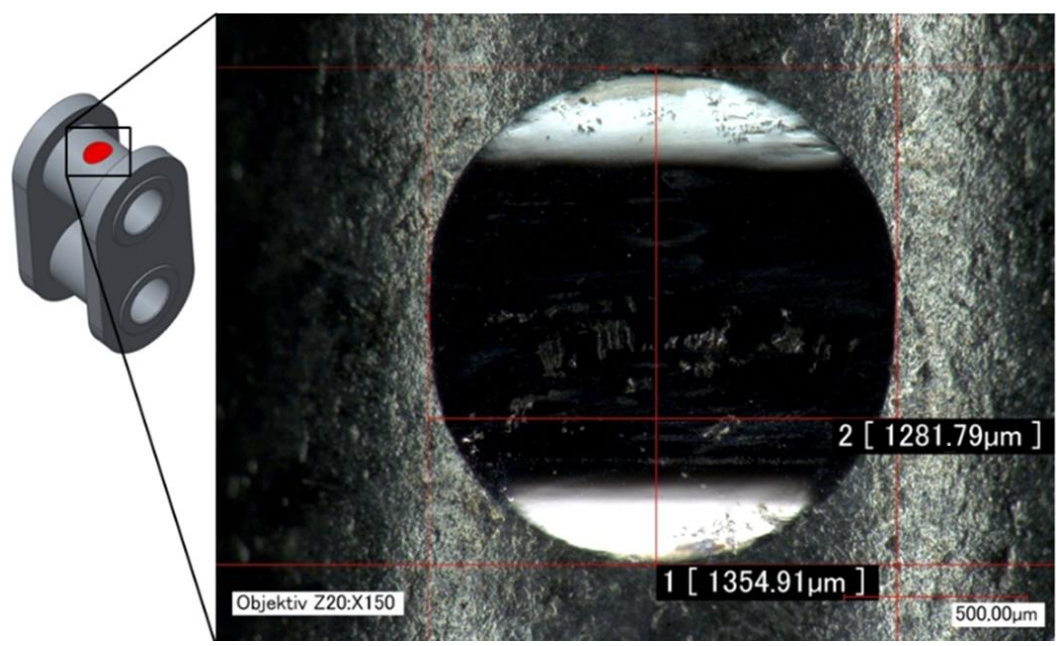

Figure 6. The two main dimensions of the wear scar on the bush 


\subsubsection{Results of the bush-on-pin measurements}

The goal of the series of measurements was to compare different oil samples in terms of friction and wear between the chain elements. If a bush-on-pin tribometer test can detect a small but significant difference between new engine lubricants, it can be considered suitable for comparative tests. The results of the same oil samples obtained by the standard-based ball-on-disc test were used as a reference (see Section 3.1.2).

During the test series, the same lubricants were used as in case of the ball-on-disc test. Three different commercially available motor oils (Castrol 10W-60, Castrol 0W-20, Shell 0W-30) and three samples of contaminated Shell 0W-30 oil with 0.5 $\mathrm{wt} \%, 1 \mathrm{wt} \%$ and $2 \mathrm{wt} \%$ carbon black (Cabot Monarch ${ }^{\circledR} 430$ ).

The comparison of the coefficients of friction measured by the two methods is shown in Fig. 7.

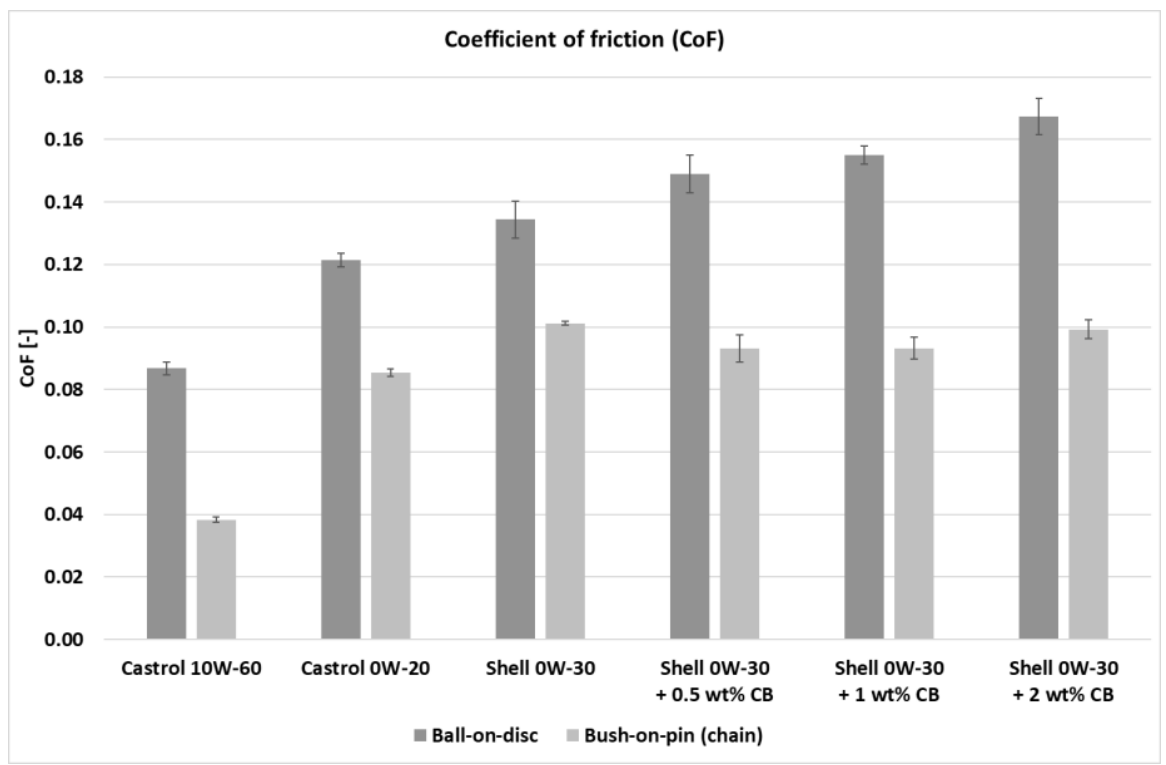

Figure 7. Comparison of coefficients of friction measured by both methods

Based on Fig. 7., it can be concluded that the bush-on-pin method reproduced the order of oils with minimal standard deviation. The standard deviation is even smaller in most cases than that of the ball-on-disc measurements taken as reference. 
The best results in both test series came with the Castrol 10W-60 oil, as due to its high viscosity it is best able to separate the contact surfaces. This oil is specifically used for high-performance engines, so the result is in line with preliminary expectations.

Wear results showed a similar trend, see Fig. 8.

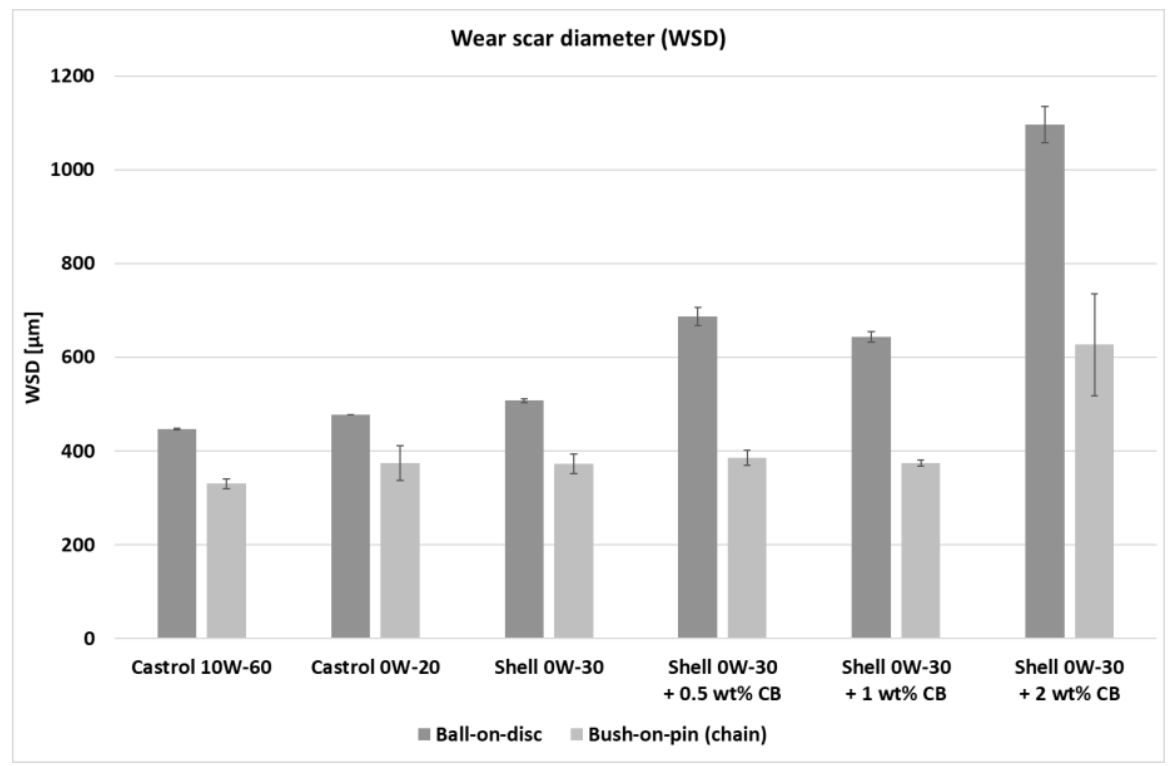

Figure 8. Comparison of wear scar diameters measured by two methods

In case of Castrol 0W-20 and Shell 0W-30 oils, the wear values are clearly higher than with Castrol 10W-60. There is no significant difference that can be detected between the two low-viscosity oils, wear results of these are in the same range in case of bush-on-pin, with higher relative standard deviation values $(10,1 \%$ by Castrol $0 \mathrm{~W}-20$ and 5,7 \% by Shell $0 \mathrm{~W}-30$ ). With bush-on-pin test, small differences cannot be detected so clearly compared to ball-on-disc method. What can be clearly stated is that in the case of Castrol 10W-60 oil the wear value is significantly lower and the standard deviation is also sufficiently small $(3,1 \%)$.

With oils mixed with carbon black - similar to ball-on-disc tests - the wear with $1 \mathrm{wt} \%$ carbon black was minimally less than with $0.5 \mathrm{wt} \%$, however, the difference is not significant. In fact, it is not significant compared to the wear measured with the unblended sample of this oil. Wear increased significantly only with the addition of $2 \mathrm{wt} \%$ carbon black, similar to ball-on-disc measurements. 
Based on these results, it can be concluded that with the present test parameters of bush-on-pin test method, the effect of a small difference between the oils (small difference between viscosity classes and additives) can be detected in wear, but not as clearly and definitely as with a ball-on-disc test. However, in the case of a larger difference in viscosity or in additive package, as well as in the case of high carbon black or soot content, a significant difference can be detected.

In turn, the differences in the coefficient of friction between the pure oils can also be detected definitely and with negligible uncertainty by both of the test methods.

\section{Conclusions}

The results of tribological experiments with chain elements show a similar trend in both coefficient of friction and wear as the ball-on-disc measurements. Minor differences can be attributed to the differences between the two tribological systems, such as geometry, material, method of lubrication, and motion conditions of the specimens.

The bush-on-pin method, just like the ball-on-disc, is suitable for evaluating the effect of oil quality, contamination and other factors on friction, wear and the life expectancy of chains.

Because the bush-on-pin method proves to be reliable when compared to the ballon-disc method, it can also be used in cases where ball-on-disc testing is not possible. In case of simple oil ranking, the ball-on-disc test is more suitable because it is much simpler and it is a standard-based test. The bush-on-pin method is expected to have a promising potential in evaluating chain materials, manufacturing technology, geometry, surface coating and quality. It would be quite expensive to produce standardized tribometer test specimens with the original material, coating and heat treatment, surface characteristics of the chain. The tribometer specimens would behave differently during heat treatment than the chain elements.

It can be concluded that it is worth using the chain measurements on tribometer to make the development of chain drives more cost-effective and environmentally friendly.

\section{References}

[1] T. Fink, V. Hirschmann, Kettentriebe für den Einsatz in modernen Verbrennungsmotoren. MTZ - Motortechnische Zeitschrift 62, (2001), pp. 796-806., in German doi: https://doi.org/10.1007/BF03227087 
[2] T. Fink, K. Elwan, Steuerkettentriebe mit innovativen Lösungen zur Steigerung der Leistungsfähigkeit, in: Kay Schintzel (Ed.) 4. Győrer Tribologie Tagung, Győr, Universitas-Győr Nonprofit Kft. (2016), pp. 47-53., in German

[3] H. Schwarze, L. Brouwer et al. Lubricant degradation and wear behaviour in a spark-ignition engine. MTZ Worldwide 69 (2008) pp. 60-67 doi: https://doi.org/10.1007/BF03226922

[4] T. Gergye, M. R. Dreyer et al., Analysis of the Wear Behavior of Combustion Engine Components Using Radionuclide-Technique. in: SAE-China, FISITA (Eds.) Proceedings of the FISITA 2012 World Automotive Congress (1) (2012) pp. 171-181.

doi: https://doi.org/10.1007/978-3-642-33841-0_13

[5] T. Gergye, M. R. Dreyer, Tribologische Untersuchung einer Steuerkette, in: Dreyer, Mathias Roman; Demmelbauer-Ebner, Wolfgang (szerk.) 2. Györer Tribologie Tagung, Györ, Universitas-Győr Nonprofit Kft., (2012) pp. 173186., in German

[6] A. Becker, D. Meffert, B. Sauer, Friction and wear investigations on single chain joints. Forschung im Ingenieurwesen 83, (2019) pp. 53-63. doi: https://doi.org/10.1007/s10010-019-00297-x

[7] H. Czichos, K. Habig, Tribologische Mess- und Prüftechnik, in: TribologieHandbuch, 3. Auflage, Vieweg + Teubner (2010) ISBN 978-3-8348-0017-6, pp. 193-195, in German

[8] A. Gummer, Cs. Fábián, B. Sauer, Experimental Investigation of Roller Chain Wear, 18th International Colloquium Tribology, Technische Akademie Esslingen, 10-12 January 2012, Ostfildern

[9] A. Gummer, Cs. Fábián, B. Sauer, Modularer Kettenprüfstand für Verschleißund Wirkungsgraduntersuchungen, 52. Tribologie-Fachtagung, 26.28.09.2011, Göttingen, in German

[10] D. Sappok, A. Gummer, B. Sauer, Experimental and analytical wear investigations of bush- and roller chain drives. 5th World Tribology Congress, WTC 2013. (2) (2013) pp. 1204-1207. 
[11] Standard Test Method for Wear Preventive Characteristics of Lubricating Grease (Four-Ball Method), ASTM D2266 - 01(2015)

[12] Standard Test Method for Wear Preventive Characteristics of Lubricating Fluid (Four-Ball Method), ASTM D4172 - 20

[13] Lubricants - Determination of tribological quantities for oils and greases Tribological test in the translatory oscillation apparatus, ISO 19291:2016

[14] Á. D. Tóth, Á. I. Szabó, R. Kuti, Tribological Properties of Nano-Sized ZrO2 Ceramic Particles in Automotive Lubricants, FME Transactions 49 (1) (2021) pp. 36-43.

doi: https://doi.org/10.5937/fme2101036T

[15] D. Uy, M. A. Ford et al., Characterization of gasoline soot and comparison to diesel soot, Morphology, chemistry, and wear, in: Tribology International 80, (2014) pp. 198-209.

doi: https://doi.org/10.1016/j.triboint.2014.06.009

[16] S. Antusch, M. Dienwiebel et al., On the tribochemical action of engine soot, in: Wear 269 (1-2) (2010) pp. 1-12.

doi: https://doi.org/10.1016/j.wear.2010.02.028

[17] E. Hu, X. Hu, et al., The role of soot particles in the tribological behavior of engine lubricating oils, Wear 304 (1-2) (2013) pp. 152-161

doi: https://doi.org/10.1016/j.wear.2013.05.002

[18] A. La Rocca, G. Di Liberto et al.: The nanostructure of soot-in-oil particles and agglomerates from an automotive diesel engine, in: Tribology International 61 (2013) pp. 80-87

doi: https://doi.org/10.1016/j.triboint.2012.12.002

[19] M. Ratoi, R. Castle et al., The influence of soot and dispersant on ZDDP film thickness and friction. in: Lubrication Science 17 (1) (2006) pp. 25-43. doi: https://doi.org/10.1002/1s.3010170103

[20] Á. D. Tóth, L. Paulovics et al., Methodenentwicklung zur Einstufung von Motorölen anhand tribologischer Eigenschaften, in: 58. TribologieFachtagung 2017: Reibung, Schmierung und Verschleiß, Forschung und 
praktische Anwendungen, Gesellschaft für Tribologie, Göttingen, Aachen, (2017) P8, in German

[21] L. Paulovics, Á. D. Tóth et al., Tribometerversuche an Steuerkettenteilen, in: 58. Tribologie-Fachtagung 2017: Reibung, Schmierung und Verschleiß, Forschung und praktische Anwendungen, Gesellschaft für Tribologie, Göttingen, Aachen, (2017) P9, in German

[22] L. Paulovics, M. Németh, J. Knaup, Alternative Verschleissmessverfahren für Steuerketten, in: Knaup, Jan (Ed.) 5. Györer Tribologie- und Effizienztagung, Győr, Universitas-Győr Nonprofit Kft., (2018) pp. 199-216., in German

[23] Zs. M. Tabakov, L. Paulovics, Development of wear analysis of timing chain elements on a high frequency reciprocating rig, In: A. Dernóczy-Polyák (Ed.) Kutatási jelentés 2. - Research Report, Győr, Universitas-Győr Nonprofit Ltd. (2020) pp. 248-252. 